\title{
Analysis of the diversity and tissue specificity of sucrose synthase genes in the long read transcriptome of sugarcane
}

\author{
Prathima P. Thirugnanasambandam ${ }^{1,2 \dagger}$, Patrick J. Mason ${ }^{1 \dagger}$, Nam V. Hoang ${ }^{3}$, Agnelo Furtado ${ }^{1}$,
} Frederik C. Botha ${ }^{1,4}$ and Robert J. Henry ${ }^{1 *}$ (I)

\begin{abstract}
Background: Sugarcane accumulates very high levels of sucrose in the culm. Elucidation of the molecular mechanisms that allows such high sucrose synthesis and accumulation (up to $650 \mathrm{mM}$ ) is made difficult by the complexity of the highly polyploid genome. Here we report the use of RNA Seq data to characterize the sucrose synthase (SuSy) genes expressed in the transcriptome of the mature sugarcane plant.

Results: Four SuSy gene families were identified in the sugarcane Iso-Seq long read transcriptome (SUGIT) through gene annotation of transcripts that mapped to reference SuSy genes from sorghum and maize. In total, 38, 19, 14, and 2 transcripts were identified for the four corresponding SuSy genes 1, 2, 4 and 7, respectively. Comparative studies using available SuSy genes from sorghum $(1,2,4,6,7)$ and maize (1-7) revealed that the sugarcane SuSy genes were interrupted by multiple introns and that they share a highly conserved gene structure. Spatial expression of the four SuSy genes in sugarcane genotypes and in the progenitor species, Saccharum spontaneum and Saccharum officinarum, was studied in the leaf and root tissues and also in three regions of the culm tissue; top, middle and bottom internodes. Expression profiles indicated that all SuSy transcripts were differentially expressed between the top and bottom tissues, with high expression in the top tissues, lower expression in the bottom and moderate expression in the middle, indicating a gradient of SuSy activity in the sugarcane culm. Further, the root tissue had similar expression levels to that of the top internodes while leaf tissues showed lower expression. In the progenitors, SuSy7 was found to be highly expressed in S. officinarum while the other three SuSy genes had moderate expression in both the progenitors.
\end{abstract}

Conclusions: The high expression of the SuSy genes in sink tissues, the top internodes and the roots suggests functional roles in sucrose utilization to support growth. The SuSy7 gene has not been previously reported in sugarcane. As sugarcane is unique in storing such high amounts of sucrose, it is possible that there are more SuSy genes/isoforms with specific expression patterns to be discovered in this complex system.

Keywords: Sucrose synthase gene family, SuSy isoforms, Transcription, Sugarcane, Expression profiling, Sugarcane genes, Transcript diversity, Root tissue

\footnotetext{
* Correspondence: robert.henry@uq.edu.au

${ }^{\dagger}$ Prathima P. Thirugnanasambandam and Patrick J. Mason have contributed equally to this manuscript

${ }^{1}$ Centre for Plant Sciences, Queensland Alliance for Agriculture and Food Innovation, The University of Queensland, 306 Carmody Road, St. Lucia, Queensland 4072, Australia

Full list of author information is available at the end of the article
}

(c) The Author(s). 2019 Open Access This article is distributed under the terms of the Creative Commons Attribution 4.0 International License (http://creativecommons.org/licenses/by/4.0/), which permits unrestricted use, distribution, and reproduction in any medium, provided you give appropriate credit to the original author(s) and the source, provide a link to the Creative Commons license, and indicate if changes were made. The Creative Commons Public Domain Dedication waiver (http://creativecommons.org/publicdomain/zero/1.0/) applies to the data made available in this article, unless otherwise stated. 


\section{Background}

Sucrose synthase (SuSy) is widely considered as a key enzyme involved in sucrose metabolism and is probably important in carbon partitioning towards polysaccharide synthesis, sucrose turnover and an adenylate-conserving pathway of respiration [1]. Cell wall formation is inhibited in SuSy mutants in maize [2, 3], antisense carrot plants [4] and cotton seeds [5]. However, the universal role of SuSy is still unclear as normal growth occurs in knock down mutants of Arabidopsis plants [6].

Several paralogous genes of SuSy have been identified and characterized in multiple plant genomes [7-12], while very limited information on SuSy genes is available for sugarcane [13-18]. SuSy catalyzes the reversible conversion of sucrose into fructose and UDP-glucose, which are the primary substrates for respiration, starch and cell wall constituents [1, 19] and fibre development [20]. $\mathrm{SuSy}$ is reported to be active in young internodes of sugarcane stems $[16,21]$. It is also found to be more highly expressed in high sugar genotypes than in low sugar genotypes [22] wherein high levels of SuSy activity was correlated with an increase in sucrose accumulation rate and ripening. However, there are contradictory observations made in other studies (i.e. in [13, 23]) indicating no correlations between SuSy and sucrose accumulation. The reaction catalyzed by SuSy is readily reversible, and the enzyme is said to be functioning primarily in the direction of sucrose degradation (sucrose cleavage into glucose and fructose subunits) to provide sugar nucleotides for glycosylation of varied molecules. SuSy is highly correlated with sink strength in various crops like potato [24], carrot [25, 26], maize [8] and pea embryos [27]. In addition, SuSy activity is found to be associated with sugar import [28], organellar function [29] stomatal function [30], plant's response to environmental stresses and nitrogen fixation [31]. There are studies on the association of SuSy with cellulose synthases forming complexes to channel UDP-glucose towards cellulose biosynthesis [19].

The identification and subsequent characterization of different SuSy genes forms the basis for understanding their roles in the physiological, metabolic and molecular mechanisms of different growth processes in plants. At least three SuSy genes are thought to be found in most plant species encoded by a small multigene family. There are six distinct active SuSy genes in Arabidopsis [10, 32] and model legume Lotus japonicus [33]. Rice is reported to have seven SuSy genes [34] and was previously thought to have six genes [10]. Similarly, diploid cotton was reported to have seven SuSy genes [7], which was later updated to eight $[20,35]$. The pea has three SuSy genes [27]. A recent genome wide study in grapes reported five SuSy genes [36]. Maize has three distinct genes, Sh1, Sus 1 and Sus3 [9, 37]. However, the
NCBI-GenBank has seven SuSy genes (1-7) sequences for Zea mays (Zea mays annotation version 101 v 7.3, released March 2017). Similarly, the Sorghum bicolor annotation release 101v 7.4 (released June 2017) has SuSy genes 1, 2, 4, 6, and 7. Nicotiana tabacum is reported to have 14 SuSy genes [38]. The tetraploid cotton, G. hirsutum has the largest SuSy family to date, containing 15 SuSy genes [35]. SuSy genes have high structural similarity, functional diversity and are reported to have tissue specific expression during various stages of plant development. Tissue- and development stage- specific expression of SuSy is also reported in rice [10], carrot [39], poplar [40], cotton [7], maize [9, 41], sugarbeet [42] and citrus [43] implying that each SuSy gene may have a distinct role at a specific developmental stage in a specific tissue.

The sugarcane culm and roots are the major sinks in sugarcane [44]. There are two clear phases of internode growth in the culm. Using a base temperature of $18^{\circ} \mathrm{C}$ internode elongation stops after $150^{\circ} \mathrm{Cd}$ (heat units) while dry matter accumulation continues for up to $800^{\circ}$ $\mathrm{Cd}[45,46]$. By the time internode length stopped increasing, the dry weight of the internodes was still less than half its final value $[45,46]$. The pattern of carbon partitioning in the culm changes significantly during the elongation and biomass accumulation phases of the internode $[47,48]$. The water-insoluble component (primarily cell wall), and non-sucrose-water-soluble fraction (reducing sugars, amino acids and organic acids), represents approximately $90 \%$ of the total dry matter during the internode elongation phase (up to internode 5). Sucrose accumulation starts in the young internodes but accelerates sharply when internode elongation stops. In internode $10,50 \%$ of the dry mass is sucrose and this elevated sucrose comes at the expense of the other water solubles and fibre.

Sucrose synthesis in sugarcane is a continuous process and sucrose accumulation in the culm is initiated after internode elongation has stopped [14], takes place after six months of crop growth from the time of planting, coinciding with the development of stem and its elongating internodes [49] . The parenchymatous cells initially store sucrose in the vacuole which is a reversible process depending on the growth and developmental conditions [50], but in the mature culm up to $30 \%$ of the sucrose can be in the apoplast [51]. Many genes, including the SuSy genes, have been proposed to be involved in controlling sucrose synthesis and accumulation. In a few plant species such as Arabidopsis, SuSy genes have been well studied, however, in sugarcane, our understanding of SuSy genes still limited. Due to the importance of sucrose in sugarcane, the SuSy genes, especially their identity, gene structure, evolutionary mechanisms and potential functions in sugar and fibre synthesis and 
accumulation, needs to be well explored. Previous studies suggested the presence of a small gene family encoding different $\mathrm{SuSy}$ isoforms within the polyploid sugarcane, but to date characterization of the SuSy genes have not been reported, except for SuSy1 and 2 [15] and SuSy4 [52]. Recently a haplotype identification study of SuSy genes has reported five genes (1-5) in sugarcane [18]. With advances in sequencing technology, RNA sequencing (RNA-Seq) has become an effective and powerful tool for transcriptome analysis, that includes quantifying gene expression/allele-specific expression, discovery of novel transcripts and alternatively spliced genes [53].

In the current study, we report the identification and characterization of four SuSy genes (1, 2, 4 and 7) expressed in the sugarcane transcriptome derived from various tissues of a mature crop (at 10 months after planting) and their expression patterns at the transcriptome level. In addition, a set of transcriptomes (RNA-Seq read data) from three different regions of the culm (mainly top, middle and bottom internodes), leaves and root tissues from another independent experiment (Mason et al., unpublished) was utilized for checking the tissue specific expression of the four SuSy genes identified from the sugarcane transcriptome. The results presented in this work provide new insights into the functional diversity of the sugarcane SuSy gene family in response to growth and development and most importantly, sucrose synthesis and accumulation as the crop matures and stores maximum levels of sugar at this growth stage. The analyses in this study mainly focused on the gene identification, exon/intron organization, evolutionary relationship, and tissue-specific expression patterns of the sugarcane SuSy genes identified. Sugarcane is an autopolyploid with each locus having multiple haplotypes from 8 to 14 which is an indication of the level of heterozygosity that is likely to have contributed to the high biomass yield of sugarcane $[18,54]$. As sugarcane is unique in storing such high amounts of sucrose, it is possible that there are more SuSy genes/ isoforms with specific expression patterns suggesting the need for further studies. A new isoform SuSy7 is reported for the first time in sugarcane bringing the number of SuSy members from 5 [55] to 7, although SuSy 3, 5,6 were not found in our study.

\section{Materials and methods}

\section{Database search and bioinformatics analysis}

A search for SuSy genes in the sugarcane Iso-Seq transcriptome database SUGIT, previously reported in [56], was performed in order to identify all members of the SuSy gene families. The strategy used to obtain the available members of SuSy gene family in the transcriptome was as follows. Using CLC Genomics Workbench version 10 (CLC-GWB, CLC Bio-Qiagen, Aarhus, Denmark), the SuSy gene sequences from Sorghum bicolor and Zea mays were used as query to search against the SUGIT database. Sequences of some of the SuSy genes from Arabidopsis, rice, wheat and bamboo were also used as queries in order to obtain a comprehensive list of putative SuSy genes from the transcriptome. All sequence data used in this study were collected using the keyword "sucrose synthase" in the NCBI-GenBank and UniProt databases. Initially, the sequences were mapped using the large gap mapping tool in CLC-GWB with length fraction (LF) (0.8) and similarity fraction (SF) of $(0.5)$ in order to retrieve the sequences with less stringency followed by a LF of 1 and SF of 0.9 with the retrieved reads with their respective reference SuSy genes. Other bioinformatics analyses, such as amino acid composition and conserved domains of the SuSy genes were performed using the Expert Protein Analysis System (ExPASy) (http://www.expasy.org/tools/ protparam.html). Substitutions per synonymous site (Ks) and the non-synonymous divergence (Ka) values for each gene among the transcripts were calculated using the Nei-Gojobori method [57] implemented in MEGA v.7 [58].

\section{Gene structure and phylogenetic relationship analysis}

The alignment of SuSy genes with references were performed using Geneious v.9 (https://www.geneious.com/). The schematic structures of SuSy genes, based on exon/ intron data, were produced using Geneious v.11 with the reference gene sequences. The genomic location of each SuSy gene was determined using GBrowse and BLAST tools based on scaffold information for Sorghum bicolor available from Phytozome v12.1. Predicted conserved domains were screened within the deduced amino acid sequences of corresponding SuSy genes using the InterProScan web server (https://www.ebi.ac.uk/interpro/) and PROSITE (https://prosite.expasy.org/). The MEME suite was used for predicting motifs on the SuSy amino acid sequences (http://meme-suite.org/tools/meme). The parameters were set as follows: zero or one occurrence of a single motif per sequence; 30 as the maximum number of motifs to find. All other parameters were set at default. The open reading frame (ORF) lengths of the genes were analysed using the ORF Finder in NCBI. A phylogenetic tree was generated using the full-length protein sequences of the SuSy genes of sorghum, rice and maize along with the sugarcane SuSy genes 1, 2, 4 and 7. A total of 24 sequences were used for phylogeny the details of which are listed in the Table 1. Multiple alignment of the nucleotide and deduced amino acid sequences were performed using the programs ClustalW available in the MEGA 7.0 phylogeny program (http:// www.megasoftware.net) with default parameters. The phylogenetic tree of deduced SuSy proteins was 
Table 1 Sequences used for phylogenetic analyses from sugarcane, sorghum, rice and maize

\begin{tabular}{|c|c|c|c|c|c|c|c|c|}
\hline \multirow[t]{2}{*}{ Gene } & \multicolumn{2}{|c|}{ Sugarcane } & \multicolumn{2}{|c|}{ Sorghum } & \multicolumn{2}{|c|}{ Maize } & \multicolumn{2}{|l|}{ Rice } \\
\hline & $\overline{\text { A.A }}$ & Accession & $\overline{\text { A.A. }}$ & Accession & A.A. & Accession & A.A. & Accession \\
\hline Susy 1 & 816 & - & 816 & XP021305168 & 816 & NP001105411 & 816 & AEX32874 \\
\hline Susy2 & 802 & - & 802 & XP021312610 & 802 & NP001105323 & 808 & AAL31375 \\
\hline Susy3 & - & - & - & - & 809 & AAM89473 & 816 & ABL74561 \\
\hline SuSy4 & 809 & - & 809 & XP002465303 & 809 & XР008655408 & 809 & AEX32877 \\
\hline SuSy5 & 837 & AGT16515 & - & - & 852 & A0A1D6GWZ8 & 855 & AEX32878 \\
\hline SuSy6 & - & - & 863 & XP021315397 & 849 & XP008679107 & 857 & XP015626470 \\
\hline Susy7 & 857 & KF184934 & 855 & XP021305179 & 857 & XP008645119 & 855 & AEX32880 \\
\hline
\end{tabular}

A.A. - protein length in amino acids; Accession -NCBI-GenBank accession numbers

constructed by neighbour-joining algorithm with a bootstrap of 1000 replicates [59].

\section{Tissue specific expression of SuSy genes}

The tissue-specific expression profiles of SuSy genes 1, 2, 4 and 7 were examined in sugarcane hybrid genotypes Q208 ${ }^{\mathrm{A}}$ and $\mathrm{KQ} 228^{\mathrm{A}}$. KQ228 is a commercial, high yielding, early to mid-maturing cane, developed by Sugar Research Australia (SRA); parentage Q135 x QN62-1232. Q208 is a commercial, high yielding cane, with moderate tolerance to herbicides, this cane was also developed by SRA: parentage QN80-3425 x CP74-2005. Expression profiles of the SuSy gene transcripts $(1,2,4$ and 7) were defined using a set of RNA-Seq data derived from leaves 1 and 5 (where leaf $1 \mathrm{I}$ is the first visible dewlap), top (3-5), middle (10-12) and bottom (lowest 4) internodes, and root tissue. For leaf samples, the midribs were removed and leaf lamina cut into segments. Internode samples from harvested culms were immediately cut into $0.5 \mathrm{~cm}$-thick slices, followed by the removal of the rind and diagonal separation of the remaining pith into small $0.5 \mathrm{~cm}$ cubes, using a pair of secateurs. Internode samples were collected in internodal regions of 3 samples, which were bulked following extraction. The immature and mature root samples were collected from potted sugarcane plants. All the samples were snap-frozen in liquid nitrogen, and stored at $-80^{\circ} \mathrm{C}$ until RNA extraction. In total, 6 (root), 12 (leaf) and 54 (internode) samples were processed. After bulking there were a total of 36 RNA samples (18 internode, 12 leaf and 6 root). RNA extractions were conducted using the combined Trizol kit and RNeasy Plant minikit methods as described in [60] and checked for purity using an Agilent chip and Agilent Bioanalyser 2100 (Agilent Technologies, USA). Sufficient purity was obtained in all tissues for Illumina RNA-Seq application. RNA Seq was performed using an Illumina HiSeq 2000 at the Queensland Brain Institute, University of Queensland, Australia. Three replicated individual RNA-Seq reads were obtained for each tissue. Read adapters and quality trimming and all other downstream processes were performed in CLC-GWB with a quality score limit $<0.01$ (Phred Q score $\geq 20$ ), allowing a maximum of two ambiguous nucleotides, and removing reads below $75 \mathrm{bp}$. Paired end reads were counted as a single read in the RPKM algorithm. Details of RNA-Seq reads from various tissues are given in the Additional file 1: Table S1. For obtaining the expression values for individual SuSy genes in RPKM, RNA-Seq analyses were performed using the transcriptome reference database SUGIT with 0.8 and 0.8 as LF and SF settings respectively for each of the three replications for a sample. The experiments were carried out individually and the RPKM values for SuSy transcripts were obtained from each tissue and each replication, from the normalized reads of 40 million across the samples (as the lowest among the read counts, Additional file 1: Table S2) to avoid biases and make the expression values comparable across the tissues. In addition, the expression of the SuSy genes was checked in culm transcriptomes (top, middle and bottom pooled) from the progenitors $S$. spontaneum and S. officinarum, from another study [61] and in a set of high and low sugar genotypes (14 genotypes, differing in sugar and fibre contents) [62]. For visualizing of the expression pattern of SuSy genes, the average RPKM values of three replicates (Additional file 1: Table S2) were analysed in Microsoft Excel 2013. The heat maps of SuSy gene expression were generated by Pheatmap v1.0.8 R package $[63,64]$ using the $\log 2$-scaled $(\mathrm{RPKM}+1)$ values. The expression data is further validated using One way ANOVA and Tukey's tests available from the SPS stats v.23 and heat maps were generated for the FDR corrected $p$-values.

\section{SuSy gene analysis using the draft reference genome from Saccharum hybrid cultivar SP80-3280}

The draft reference genome from Saccharum hybrid cultivar SP80-3280 which is available from the NCBI database under the BioProject accession PRJNA272769 [65],was used as a reference genome for the SuSy transcript read mapping. Mapping settings were 0.5 to 0.8 for the similarity fraction and 0.8 for the length fraction. These settings were used to find the genomic sequences for other SuSy genes, present if any. 


\section{Results}

Identification of SuSy genes in sugarcane transcriptome From the sugarcane transcriptome reference database SUGIT, 74 transcripts matching with the SuSy reference genes were retrieved (Additional file 1: Table S3; Additional file 2: Figure S1). They were classified into four groups, depending upon the sequence similarity. Four full-length genes of sugarcane SuSy genes SuSy1 (transcript contig c109934f1p24379), SuSy2 (transcript contig c99109f1p142868), SuSy4 (transcript contig c81016f2p32950) and SuSy7 (derived from transcript contigs c96232f1p0928 and c65347f1p02616) were identified for gene structure, comparative and phylogenetic studies. Using a BLAST search against the sorghum genome, it was found that SuSy1 and 4 are located on chromosomes 1, while SuSy2 and 7 are on chromosome 10 (Table 2). The individual SuSy gene transcripts (one full-length transcript for each gene is described here, although variations might be present within the transcripts for each gene. For example, the 19 transcripts for SuSy1 gene were $95.22-100 \%$ similar to each other. The molecular weights of the proteins encoded by SuSy genes 1, 2, 4 and 7 were 93, 91, 96 and $97 \mathrm{kDa}$, respectively. SuSy2 was the highly represented gene with 38 transcripts while there were only two transcripts of SuSy7. There were about 19 and 14 transcripts of SuSy1 and SuSy4 respectively. Only for SuSy2, reference genomic sequence from sugarcane was available to infer the exon -intron structure, while for others, reference sequences from Sorghum and Zea mays were utilized. Each gene had a distinct structure with regard to intron and exon placement (Fig. 1a-d). The results obtained from NCBI-CDD search and InterProScan tools indicated two domains; the glycosyl transferase (GT1) and sucrose synthase domain (SS) characteristic of SuSy proteins. However, these vary in position among different SuSy proteins (Fig. 2a-d) and PROSITE domains distribution throughout the full-length protein sequences (Fig. 3a-d). The alignment of all the four SuSy gene transcripts with reference genes are shown in the Additional file 2: Figure S2, S3, S4 and S5.

\section{SuSy 1}

There were 19 transcripts matching to SuSy1 reference genes. These transcripts ranged from 909 to $4438 \mathrm{bp}$ in size. The deduced protein was 816 amino acids in size corresponding to the coding sequence of $2448 \mathrm{bp}$. There were two domains, SS domain spanning from $20^{\text {th }}$ amino acid isoleucine to the $558^{\text {th }}$ amino acid tyrosine. The GT1 spanned from $283^{\text {rd }}$ asparagine till $766^{\text {th }}$ methionine. The ATP binding domain was present between $306^{\text {th }}$ glycine till $683^{\text {rd }}$ threonine. SuSy1 showed $99 \%$ similarity with reference genes from sugarcane (AGI56230.1), sorghum (XP_002465161.1) and maize (XP_008659017.1).

\section{SuSy2}

There were 38 transcripts matching to SuSy2 reference genes. These transcripts ranged from 409 to $4652 \mathrm{bp}$ in size. The deduced protein was 802 amino acids in size corresponding to the coding sequence of $2406 \mathrm{bp}$. The SS domain began from $15^{\text {th }}$ amino acid leucine to the $550^{\text {th }}$ amino acid tyrosine. The GT1 domain spanned from $275^{\text {th }}$ asparagine till $758^{\text {th }}$ methionine. The ATP binding domain was present between $297^{\text {th }}$ glycine till $675^{\text {th }}$ threonine. The full-length reference gene for Saccharum SuSy2 in NCBI is 7771 bp longer with 1-16 exons (accession number AY118266). About 20 SuSy2 transcripts were found to have 16 exons, and few of them were found to retain introns in certain cases, when aligned with the full-length Saccharum SuSy2 reference gene.

\section{SuSy4}

There were 14 transcripts matching to SuSy4 reference genes. These transcripts ranged from 501 to $3255 \mathrm{bp}$ in size. The deduced protein size was 809 amino acids corresponding to the coding sequence of $2428 \mathrm{bp}$. The SS domain was found to be located from $16^{\text {th }}$ amino acid valine to the $553^{\text {rd }}$ amino acid tyrosine. The GT1 spanned from $277^{\text {th }}$ asparagine till $763^{\text {rd }}$ methionine. The ATP binding domain was present between $301^{\text {th }}$ glycine till $679^{\text {th }}$ threonine.

\section{SuSy7}

There were 2 transcripts matching to SuSy7 reference genes. One of the transcripts was $928 \mathrm{bp}$ while the other was $2632 \mathrm{bp}$ in size. The protein size was 857 amino acids corresponding to the coding sequence of $2568 \mathrm{bp}$. The SS domain spanned from $17^{\text {th }}$ amino acid methionine to the 558th amino acid tyrosine. The GT1 domain spanned from $283^{\text {rd }}$ asparagine till $767^{\text {th }}$ valine. The

Table 2 Characterization of the four SuSy genes identified in the SUGIT transcriptome database

\begin{tabular}{llllll}
\hline Gene & Chromosome (with respect to Sorghum) & Molecular weight (Da) & $\mathrm{pl}$ & Protein length (aa) & Transcript length (bp) \\
\hline Susy 1 & 1 & $93,767.18$ & 6.13 & 816 & 2409 \\
Susy2 & 10 & $91,766.90$ & 5.82 & 802 & 4652 \\
Susy4 & 1 & $96,244.03$ & 6.88 & 809 & 2950 \\
Susy7 & 10 & $97,791.07$ & 7.80 & 857 & 2632 \\
\hline
\end{tabular}


a

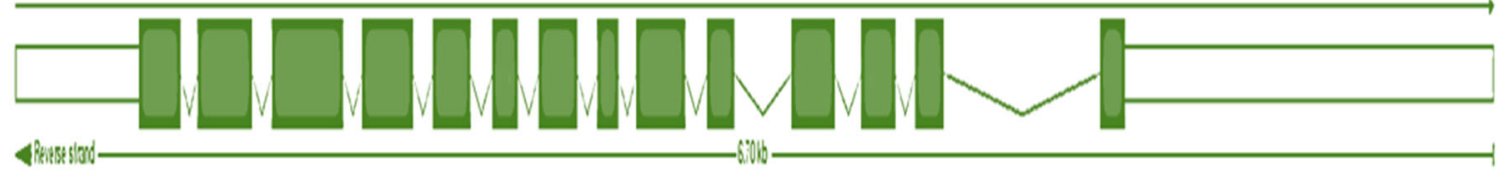

b

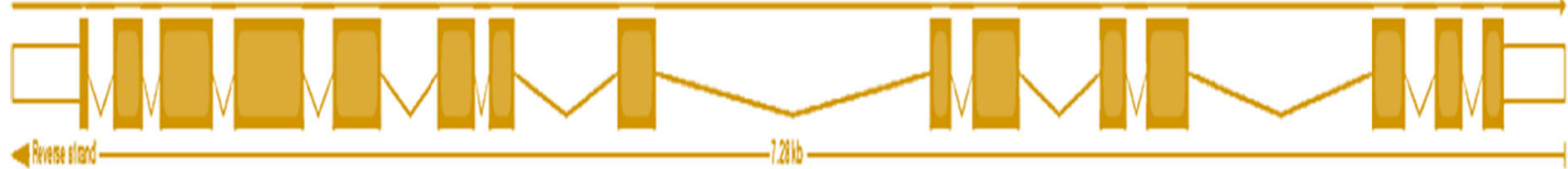

C

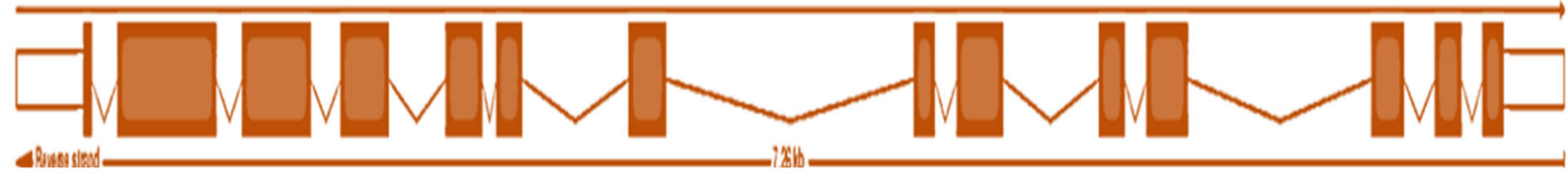

d

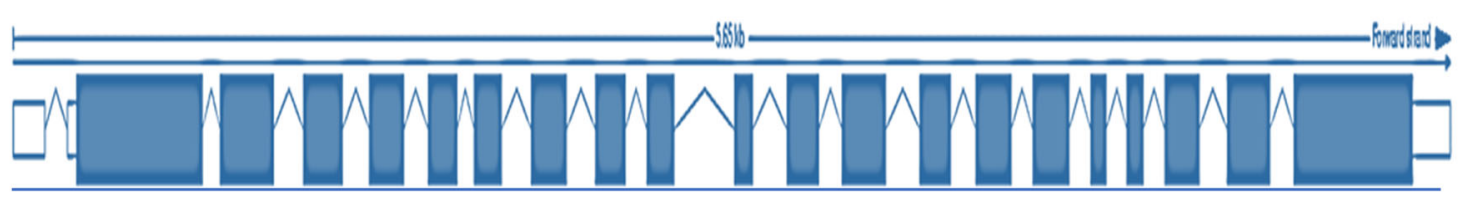

Fig. 1 Schematic representation of exon-intron structure of the four SuSy genes identified from the sugarcane transcriptome SUGIT. Using Blast in the Ensembl plants database with Sorghum bicolor and Zea mays as reference genomes, the gene structures were predicted. The boxes and lines represent exons and introns respectively and the empty boxes represent UTR regions. a SuSy1, b SuSy2, c SuSy4 and d SuSy7

ATP binding domain was present between $306^{\text {th }}$ glycine till $685^{\text {th }}$ threonine. The full-length sequence information for the SuSy7 protein was derived from two transcripts (the longer transcript was short of the initial 53 amino acids and the other transcript was incomplete in the $3^{\prime}$ end).

\section{Comparative studies of SuSy genes in sugarcane, sorghum and related genera}

The Ka/Ks ratios for the transcripts of SuSy genes were $<1$ revealing that these genes evolved under negative or purifying selection (Additional file 1: Tables S4, S5 and S6). To study the sequence similarity and evolutionary relationship among the SuSy gene family members in sugarcane, a phylogenetic tree was generated using the full-length protein sequences of the SuSy genes from sorghum, rice and maize along with the sugarcane SuSy genes 1, 2, 4 and 7 (Fig. 4a). The MEME suite identified motif positions for each member that were highly conserved without any insertions or deletions (Fig. 4b) when the motif to be predicted was set below 25 . However, a motif prediction for 30 resulted in minor variations that helped differentiate among the gene families. As expected the phylogenetic tree revealed a close relationship among the orthologous SuSy gene families. There were two distinct clades with SuSy1, 2, 3, 4 forming one clade, and SuSy5, 6 and 7 forming another. In addition, the conserved exon-intron structures of the SuSy genes across the monocots species available in Phytozome using GBrowse-BLAST tool with sorghum genome as the reference were shown in Additional file 2: Figure S6.

\section{Expression profiling of SuSy genes in various tissue transcriptomes}

The expression values ( $\log 2-$ RPKM values) were obtained for the four genes and heat maps were generated to visualize the expression profiles (Fig. 5a and b). All four isoforms were highly differentially expressed between the top and bottom internodes with the top internode having very high expression of SuSy genes, while the bottom showed very low levels of expression. The middle internode had moderate expression, thus indicating a gradient of SuSy expression with high, moderate and low expression in top, middle and bottom internodes respectively. However, the expression of SuSy4 in the middle internode was found to be higher than the top and bottom internode (genotype Q208 ${ }^{\mathrm{A})}$ or equal to the top and bottom internodes (genotype KQ228 ${ }^{\mathrm{A}}$ ). The leaves showed very low expression levels for all the four $\mathrm{SuSy}$ genes while the roots displayed very high levels similar to that of the top internode. The top internode had the highest expression levels of SuSy genes 1, 2 and 7 , followed by the root tissues, while the middle internode showed high expression levels for SuSy4 only in genotype Q208. In KQ228 genotype there was also significantly higher expression of SuSy7. The expression 


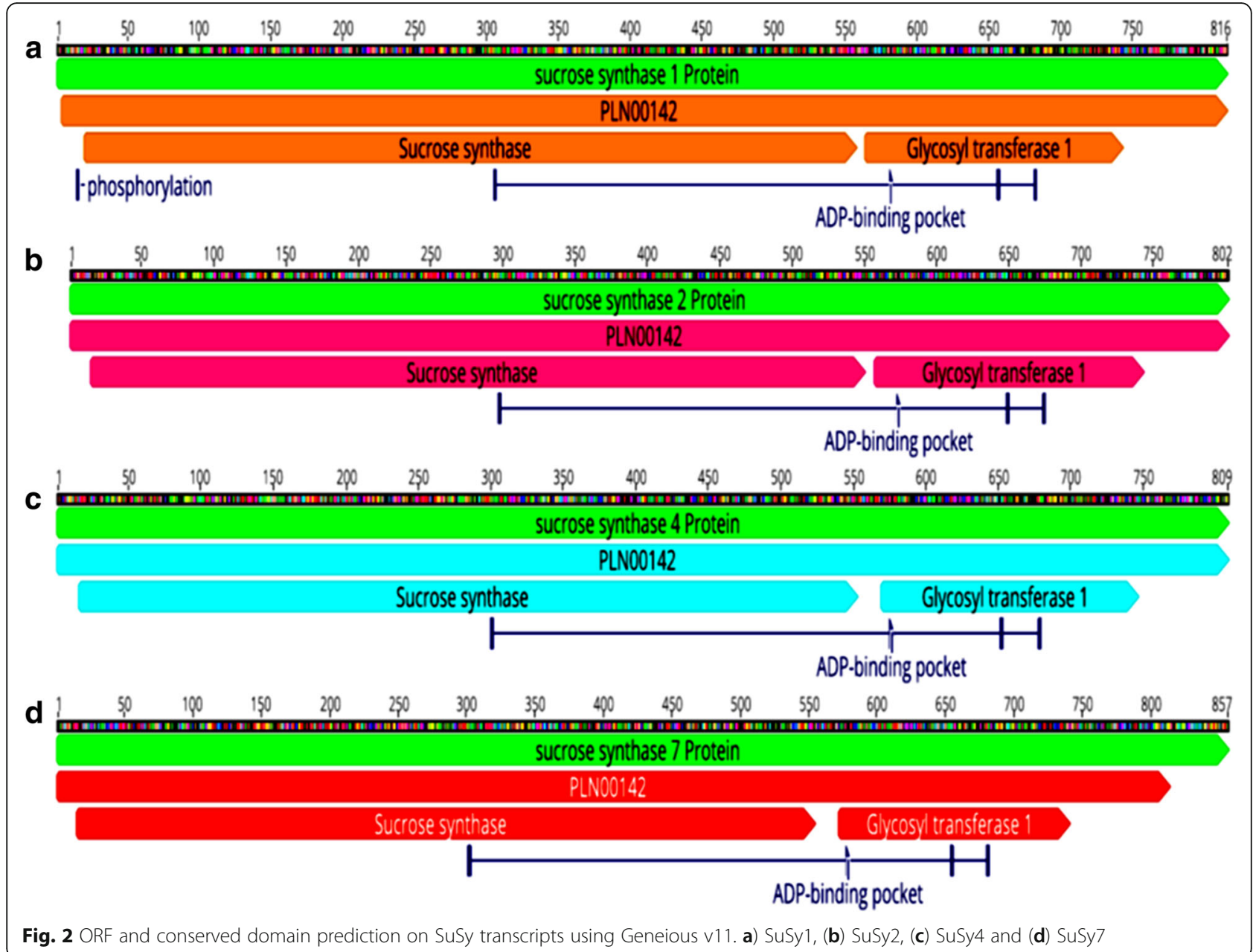

profiles were mostly consistent in both the genotypes Q208 ${ }^{\mathrm{A}}$ and $\mathrm{KQ} 228^{\mathrm{A}}$, across all the tissues used for the analyses and were statistically validated (Additional file 1: Tables S7, S8; Additional file 2: Figure S7, S8).

In case of the progenitor species $S$. officinarum and $S$. spontaneum, the expression of SuSy transcripts is shown in the Fig. 6. SuSy7 (c96232f1p0928) transcript showed highest expression in S. officinarum. The other SuSy7 transcript (c65347f1p02616) also showed high expression in S. officinarum. There were few S. spontaneum specific SuSy1 transcripts (c81187f1p11415, c87566f2p02873, c90355f8p113016) and S. officinarum specific SuSy1 transcripts (c36015f2p11118 and c71489f1p01756). In general, SuSy2 transcripts were found to be highly expressed in $S$. officinarum than S. spontaneum.

SuSy gene analysis using the sugarcane SP80-3280 reference genome

Using reference genes from sorghum and maize, the genome sequences of the sugarcane cultivar SP80-3280 was checked for the presence of the full-length sequences for SuSy genes 3, 5 or 6. When the SuSy5 sequence from Zea mays was used for mapping, two genomic reads (JXQF01182951 and JXQ01195768) mapped with a consensus of 504 and 2104 respectively. This sequence was found to have $60 \%$ query coverage and $98 \%$ similarity with SuSy7 and 51\% query coverage and $100 \%$ similarity with SuSy5.

\section{Discussion}

The sequencing of plant genomes and transcriptomes has led to the rapid identification of genes and their functional characterization. The transcriptomes are especially helpful in the identification of temporal and spatially differentially expressed genes from plants whose genomes are yet to be sequenced. Also, comparative genomic approaches are a great tool in working with less explored genomes. Availability of the complete genomic sequence for Arabidopsis and rice facilitated the identification of a total of six SuSy genes in each of the two plants, representing the entire SuSy gene members of dicots and monocots. The number of SuSy genes in most of the plants could not be exactly determined due to the inadequate coverage of genome sequencing. Sugarcane a 


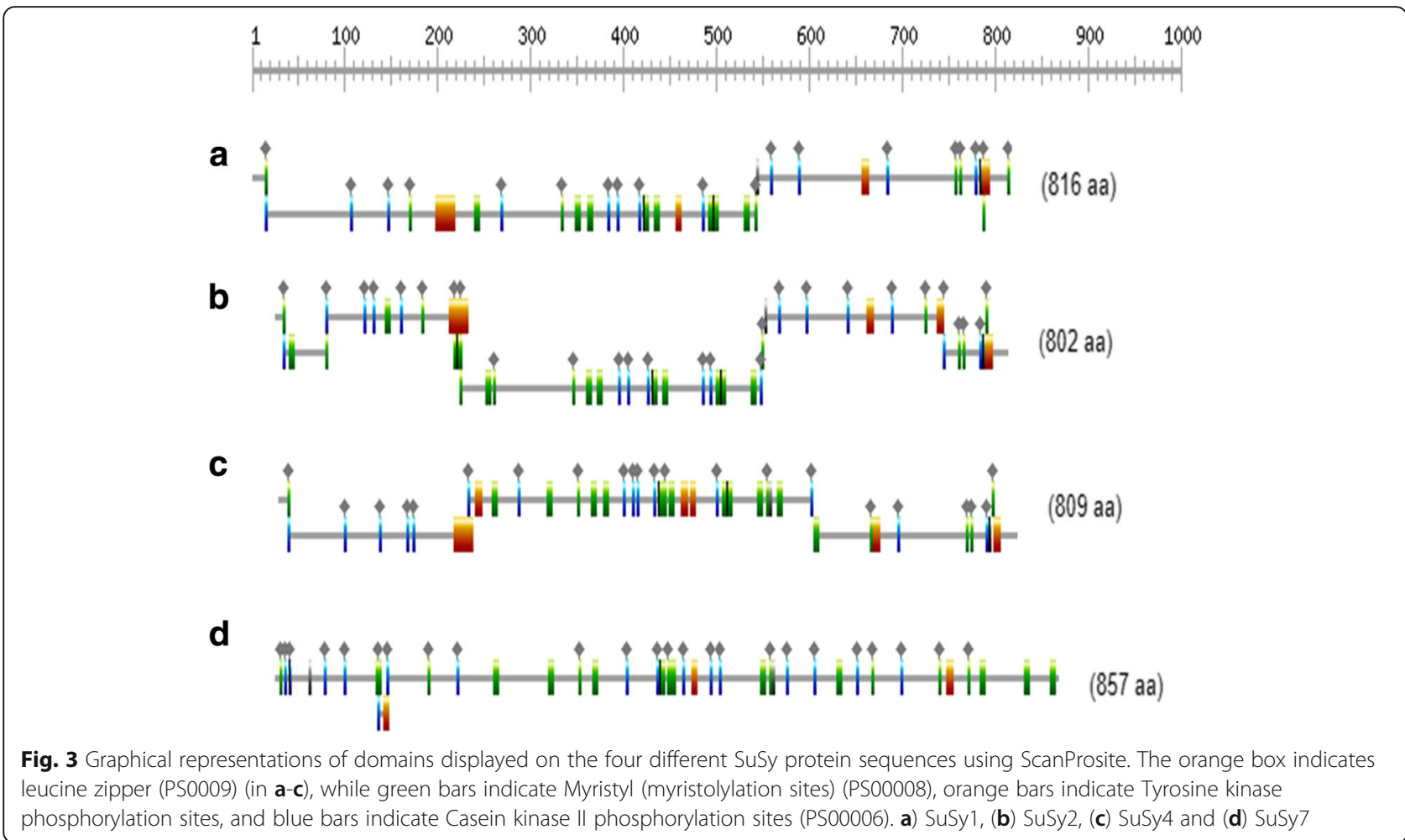

crop that accumulates high levels of sugar is expected to have more distinct SuSy genes than Arabidopsis, rice or any other crop. Previously five distinct genes encoding different types of sugarcane SuSy isoforms have been characterized at the genomic level with the help of sorghum sequences [18]. Our present work using the long-read, isoform specific transcriptome database searching brings the number of presently known members of the SuSy gene family in sugarcane to at least seven, similar to sorghum, rice, maize, cotton, etc. although other gene families (3, 5 and 6) are yet to be identified. As no adequate information is available for SuSy transcripts in sugarcane the studies of their gene structure, evolutionary relationship as well as their expression patterns provide an important step towards understanding their possible functions in different growth stages and in the composition of sugar and fibre. In a crop like sugarcane, this could get further complex, as there are reportedly 8-14 alleles for a gene and highest sucrose contents as storage sugar.

In duplicated gene families, the homologous genes are reported to have conserved exon intron structure despite having low sequence conservation which can be applied to study their evolutionary relationships $[66,67]$. In the present work, comparative screening of SuSy genes revealed that the number and position of introns was highly conserved among SuSy genes in sugarcane and other related monocot plant species. The SuSy genes 1, 2, 4 and 7 identified in this study had distinct gene structures with exon numbers ranging from 14 to 21 (SuSy1-14 exons, SuSy2-16 exons, SuSy4-14 exons and 7-21 exons), interrupted by multiple introns. The availability of full-length reference gene for SuSy2 helped identify exon-intron structure and intron retentions (or pre-mature mRNA transcripts) in certain transcripts which was not observed in other SuSy genes due to the lack of such longer, complete reference genes. The full-length sequences without the use of assembling may be probable isoforms of the gene which were not identified in the previous studies. Within the SuSy gene family, the transcripts had $95-100 \%$ similarity at the nucleotide and protein levels. The $\mathrm{Ka} / \mathrm{Ks}$ ratios for the transcripts of SuSy genes were $<1$ revealing that these genes evolved under negative selection that can remove deleterious mutations and result in stabilization of genes. This has probably ensured that the SuSy gene sequences have been conserved across evolutionary history of sugarcane, making them essential for growth and development. The Ka /Ks analysis further showed that the SuSy genes 1,2, 4 and 7 were highly similar to each other with more than $60 \%$ similarity except for SuSy7 which had a slightly less similarity with others $(58-59.5 \%$, Additional file 1: Table S9). Another interesting feature observed in SuSy transcripts is the presence of long 5'UTR regions especially in the SuSy1 and 2 gene transcripts. The $5^{\prime}$ UTR region was found to be as long as $3000 \mathrm{bp}$ in some of the SuSy2 transcripts (Additional file 2: Figure S9). The presence of a long 5' UTR in the SuSy 


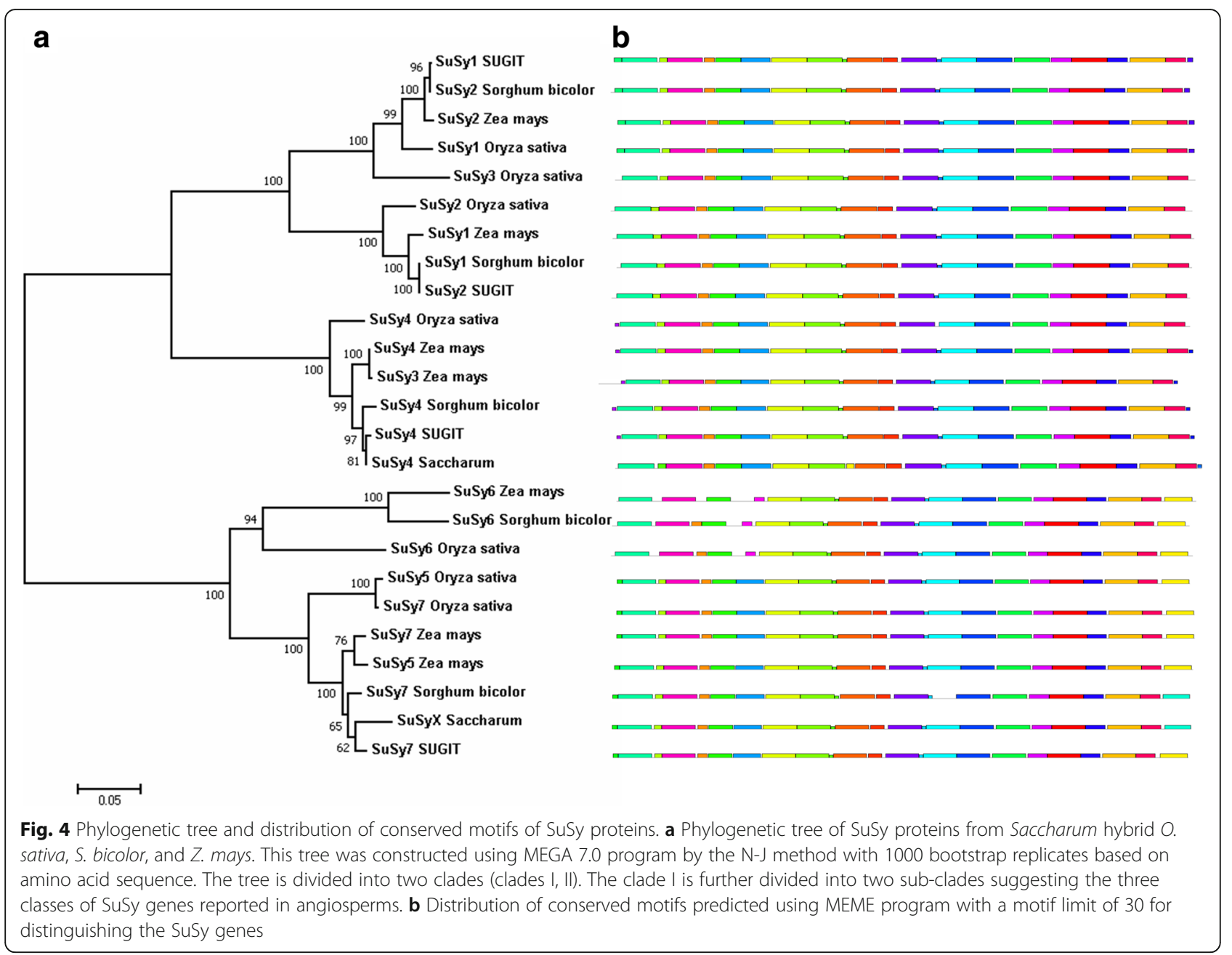

genes was reported in many crop plants [34, 68-70] and differences in the $5^{\prime}$-UTRs and 3'-UTRs among SuSy gene family members was reported in poplar [71] however in sugarcane, this is the first report of such occurrence. The functional significance of this UTR region is not well characterized in any of the crops though a few reports studied the importance of the long $5^{\prime}$ and 3'UTRs in the localization or tissue specific expression of SuSy4 transcripts in potato [72]. The results obtained from NCBI-CDD and InterProScan tools indicated two domains [73], the glycosyl transferase and sucrose synthase domains characteristic of SuSy proteins, however varying in the position of residues among the four different SuSy proteins. Some of the SuSy transcripts had only glycosyltransferase domain (full-length coding sequence with start and stop codons) and the functionality and the regulation of these transcripts are yet to be studied.

A phylogenetic tree was constructed for the SuSy genes identified in this study along with the closely related SuSy gene sequences from sorghum, maize and rice (for an evolutionary relationship among these crop species, please refer review [74]). Characterization of SuSy genes other than 1, 2 and 4 are not yet reported for sugarcane. The UniProt database had a protein sequence for sucrose synthase from Saccharum hybrid R570 (accession number AGT16515) which when analysed was found to be closely related to SuSy5 of maize. This was included in the phylogenetic analyses as there was no SuSy5 sequence from sorghum. Similarly, there is a sequence available in NCBI under accession number KF184934 (Saccharum hybrid cultivar R570, cultivar R570 clone BAC 119B13, 4 ordered pieces, sequencing in progress), the protein sequence of which is $95 \%$ similar to SuSy7 of sorghum and SuSy7 transcript identified in this study. However, this was included in the phylogenetic analysis (labelled as "X", Fig. 3a, Additional file 2: Figure S10). Exon/intron gene structures to an extent help in the prediction of origin, relationships and possible function of different SuSy genes [7]. The SuSy genes of angiosperms could be subdivided into three distinct subgroups, arbitrarily designated as class I, II and III $[18,75]$. The phylogenetic tree in our study clearly 


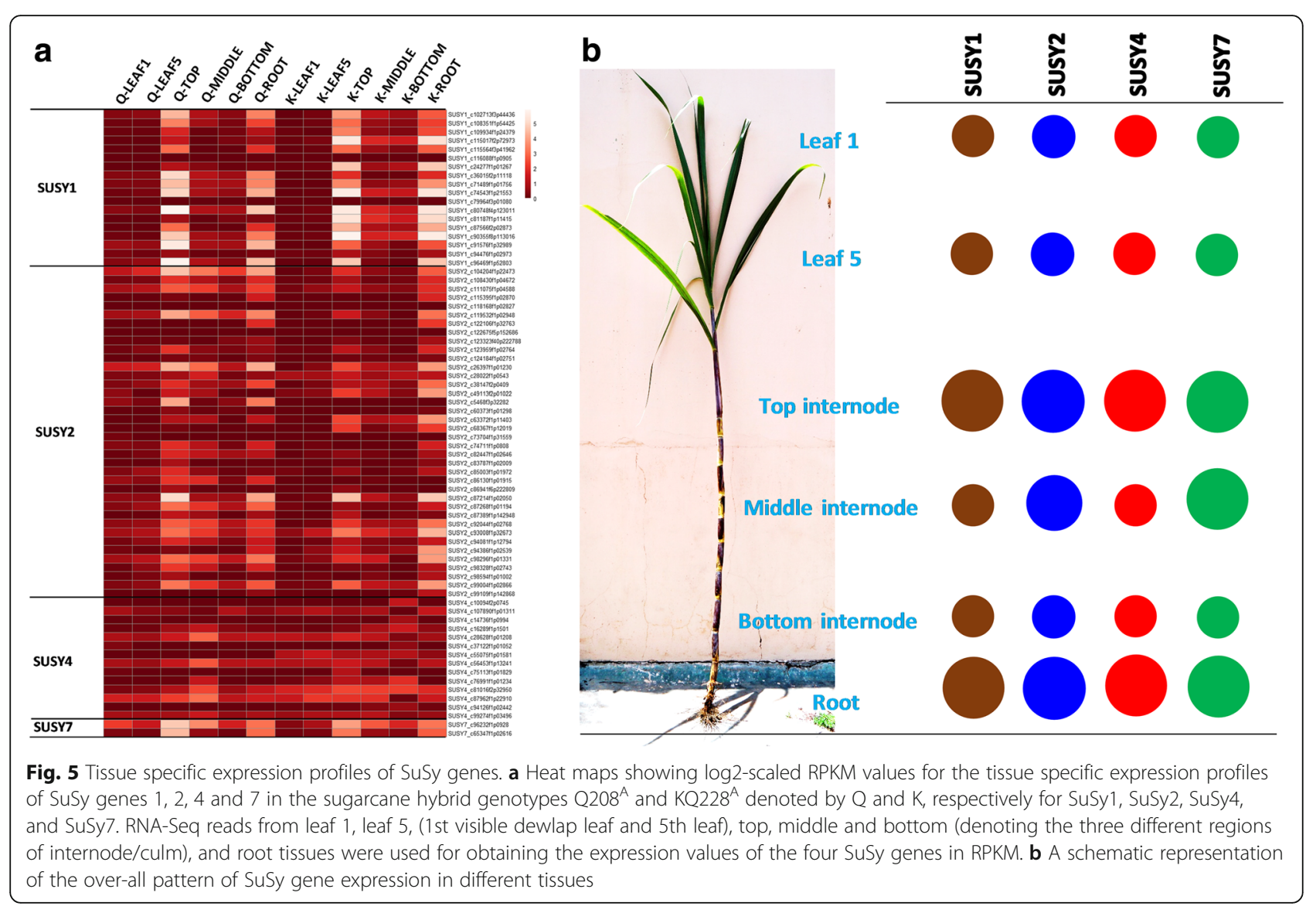

distinguished the members into two separate clades. The clade one was sub divided into two which had two sub-clades of SuSy sequences. One sub-clade was composed of SuSy1 and 2 sequences. The other sub-clade was composed of SuSy3 and 4, while the other clade was formed by SuSy5, 6 and 7 sequences suggestive of three classes of SuSy genes. Phylogenetic analysis of cotton SuSy genes and other plant homologues classified the SuSy genes into three distinct families as Sus I, II and III, respectively [18]. Such a classification is currently lacking in sugarcane as many of the SuSy gene members are yet to be characterized. In sugarcane, sorghum, rice and maize, SuSy1 shares more than $90 \%$ similarity with SuSy 2 while SuSy5 and 6 shares $80 \%$ similarity, with the variation mainly present in the $\mathrm{C}$ terminal and $\mathrm{N}$ terminal regions of the proteins (Additional file 2: Figure S11). The $\mathrm{N}$ terminal variations might be attributed to different localization signals [76] while $\mathrm{C}$ terminal is reported to be highly variable in SuSy genes [77]. This further complicates the identification of SuSy genes. Even for a well-annotated crop genome like the one of maize, inconsistencies occur in the nomenclature of the SuSy genes due to the high similarity existing between/among the isoforms/transcript variants/gene family members as can be seen when a search is made for SuSy genes in the
NCBI-GenBank or UniProt databases. This is the case with sugarcane and sorghum SuSy genes found in the public databases. In rice, SuSy5 and SuSy7 were found to be near identical with only nine SNPs between their sequences and they were found to be near to each other on chromosome 4 [34]. This close relationship between SuSy 5 and 7 can be observed in the phylogenetic tree especially for rice and maize (Fig. 3a). The MEME suite identified motif positions for each member that were highly conserved without any insertion or deletion. The distribution of motifs throughout the sequences is highly conserved and only when the set limit for motif prediction was above 25, variations could be observed among the SuSy genes. This could indicate that SuSy proteins have the potential to recognize the same target genes with similar or overlapping functions in vivo [12]. However, it is also possible that different SuSy genes may have distinct, non-overlapping functions within the same cell [78].

In order to understand the potential functions of specific SuSy genes expressed in sugarcane transcriptome, the tissue-specific expression of SuSy genes were examined in various tissues including leaves, top, middle and bottom internodes of the sugarcane culm, and root in addition to the culm transcriptomes from progenitors' 


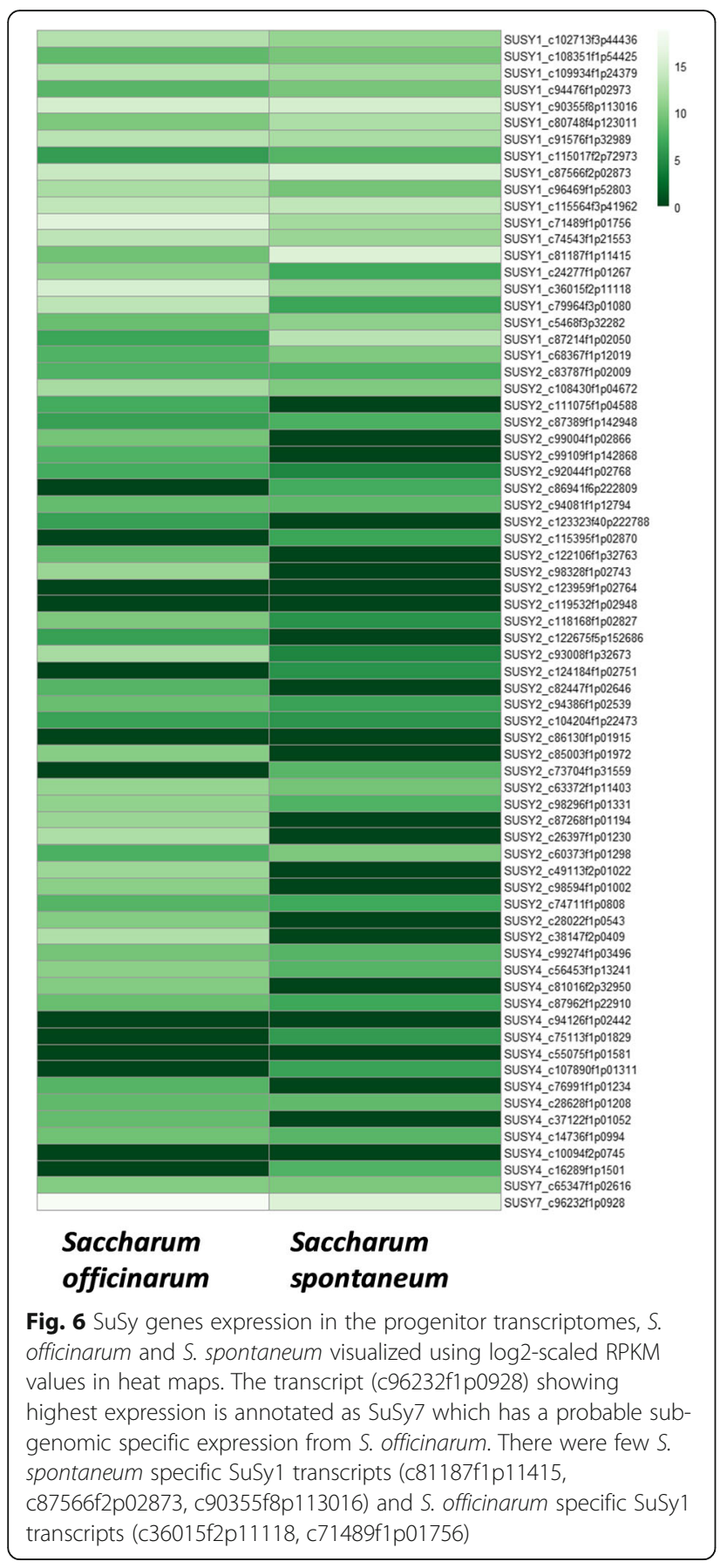

species S. spontaneum and S. officinarum. The spatial expression pattern of the four SuSy genes 1, 2, 4 and 7 was qualitatively studied from the RNA-Seq reads in the above tissues from two sugarcane genotypes, independently. All four genes were highly differentially expressed between the top and bottom tissues with the top tissue having very high expression of SuSy genes. SuSy1 showed high expression levels in top internode and root tissues, while the leaves, and the middle and bottom internodes had very little expression. SuSy2 and SuSy7 showed similar patterns in top and root tissues, while moderate expression levels were observed in the other tissues. SuSy4 did not show any tissue specific expression, however showed higher expression in the leaves than the other genes.

Overall, the top tissue is metabolically active compared to the bottom and shows higher expression of SuSy genes indicating a strong role for SuSy during the phase of growth where carbon is largely partitioned towards fibre synthesis, respiration and non-sucrose storage functions [79]. The middle internode where metabolism is largely directed towards sucrose accumulation had moderate expression. The leaves (source tissue) showed very low expression levels. The roots which are another strong sink displayed very high levels of SuSy similar to that of the top internodes. The expression profiles were consistent in both the genotypes, across all the tissues used for the analyses. Root expression (other than starch storage organs like carrot, sugarbeet) of SuSy genes have been reported earlier in rice [31], wheat and maize, however under hypoxia [80, 81]. These two tissues represent the major sinks and our data strongly supports SuSy playing a major role in driving sink strength. This in turn elevates the importance of SuSy from partitioning to driving biomass accumulation. SuSy activity was reported to be related to total sugar accumulation rate in sugarcane [82]. Sink strength is the key factor in influencing biomass accumulation and SuSy is reported to be a biochemical determinant of sink strength in developing tomato fruits [83, 84] and in potato tubers [73]. Among the SuSy genes studied, SuSy1 and SuSy2 were highly expressed in the two strong sink tissues (top internodes and root tissues), while SuSy4 and SuSy7 were expressed in all the tissues probably indicating a 'house-keeping' role for the latter. SuSy7 is a new isoform that was not reported earlier in sugarcane. In rice, an expression profile analysis of SuSy transcripts, including SuSy7 revealed that they were abundantly detected in sink tissues such as roots, flowers, and immature seeds [34]. This gene showed highest expression in S. officinarum while other isoforms showed moderate expression levels in both the progenitors probably indicating their sub-genomic origin.

The high expression levels of SuSy genes in the strong sinks is consistent with SuSy playing a major role in sucrose breakdown to provide substrate for cell wall synthesis, and provide precursors under energy conditions where available oxygen might be limiting (roots). In another study, the expression of SuSy was highly correlated with sucrose content (Additional file 2: Figure S12) with the high sugar genotypes showing high expression of SuSy genes [85].

\section{Conclusion}

The role of the SuSy genes is complex as SuSy is generally reported to be hydrolytic rather than operating in 
the synthesis direction. The high expression in sink tissues may be associated with the production of UDP-glucose to support cell wall biosynthesis in these growing tissues. Further expression studies at different developmental stages would help in elucidating the role of SuSy genes in determining the accumulation of sucrose and fibre in sugarcane. It should be noted that, although our efforts in this study, through deep sequencing and database searching, have brought the count of sugarcane SuSy gene family members to seven, we could also expect possibilities of other additional yet to be identified paralogues. More information, especially the chromosomal location of the SuSy genes in sugarcane, is needed to determine a more precise evolutionary relationship among these SuSy genes. To date, although there are few studies on SuSy genes in sugarcane, there is no systematic functional analysis or expression studies for the entire SuSy gene family. We have demonstrated differential expression of the SuSy genes in sugarcane, with respect to sink strength, tissue specificity and sub-genomic origins.

\section{Additional files}

Additional file 1: Table S1. Details of RNA-Seq reads from various tissues used for the SuSy expression study. Table S2. Raw counts for SuSy gene expression from different tissue sample. Table S3. SuSy transcripts from the SUGIT transcriptome database. Table S4. Codon-based Test of Positive Selection for analysis between SUSY1 sequences. Table S5. Codon-based Test of Positive Selection for analysis between SUSY2 sequences. Table S6. Codon-based Test of Positive Selection for analysis between SUSY4 sequences. Table S7. Log2-fold change values and FDR corrected heat map for SuSy transcripts expression in the genotype KQ228. S8. Log2-fold change values and FDR corrected heat map for SuSy transcripts expression in the genotype Q208. Table S9. Similarity percentage observed between different SuSy isoforms using Clustal W 2.1 (XLSX $362 \mathrm{~kb})$

Additional file 2: Figure S1. Identification and sequence retrieval of SuSy transcripts from the SUGIT transcriptome reference database. Shown here is the reads mapping to the reference SuSy4 gene from sugarcane using large gap mapping tool in the CLC-WB v 10. Figure S2. Alignment of nucleotide sequences of the SUGIT-SUSy1 transcripts with the reference sequences using Geneious v.11. Reference genes used in the alignment are from Sorghum accession numbers NC_012870, XM_002465116; bottom with Zea mays NC_024467 and NM_001111941. Figure S3. Alignment of nucleotide sequences of the SUGIT-SuSy2 transcripts with the reference sequences using Geneious v.11. Reference genes for alignment is from Saccharum officinarum, accession number AY118266 and its mRNA and cDNA sequences. Figure S4. Alignment of nucleotide sequences of the SUGIT-SuSy4 transcripts with the reference sequences using Geneious v.11. Reference genes used for alignment are from Zea mays accession numbers NC_012870 and mRNA and CDNA sequences of accession XM_2465268. Figure S5. Alignment of nucleotide sequences of the SUGIT-SuSy7 transcripts with the reference sequences using Geneious v.11. Reference genes used are from Zea mays accession numbers NC_024463 and mRNA and CDNA sequences of accession number XM_008646897. Figure S6. Conserved exon-intron structure across the monocots species available in Phytozome. Using BLAST tool available in the GBrowse, the SuSy transcripts were annotated with Sorghum as the reference genome. Figure S7. a. In genotype KQ228 SuSy 1, 2 and 7 have significantly different expression between each of the tissue types, based on one -way ANOVA results $p<0.01$. b. Based on tukey t-test results the expression rates of SuSy 1,2 and 7 are significantly higher in root and top internode tissue. Analysis undertaken in SPS stats v. 23. Figure S8. a. In genotype Q208 SuSy 1, 2 and 7 have significantly different expression between each of the tissue types, based on one -way ANOVA results $p<0.01$. b. Based on tukey t-test results the expression rates of SuSy 1, 2 and 7 are significantly higher in root and top internode tissue. Analysis undertaken in SPS stats v. 23. Figure S9. The 5' upstream sequence in one of the SuSy2 transcript spanning to 2243 bp with an ORF length of $2409 \mathrm{bp}$. Figure S10. Multiple sequence alignment of SuSy gene sequences used for phylogenetic analysis. Figure S11. Variations present in the $C$ terminal (A) and $N$ terminal regions (B) of the identified SuSy1, 2, 4 and 7 proteins. The $N$ terminal variations might be attributed to different localization signals while C terminal is reported to be highly variable among the SuSy genes [81]. Figure S12. The high expression level of SUGIT SuSy gene transcripts coincident with the high levels of sucrose and fiber in sugarcane hybrid genotypes. Heat maps showing log2scaled RPKM (reads per kilobase per million reads) values for expression profiles of SuSy genes 1, 2, 4 and 7 in the sugarcane hybrid genotypes (XLSX $19426 \mathrm{~kb})$

\section{Abbreviations}

CDD: Conserved domain database; CDNA: Complementary DNA; GDP: Guanosine diphosphate; GTP: guanidine tri phosphate; mRNA: Messenger RNA; NADP: Nicotinamide Adenosine diphosphate; NCBI: National Center for Biotechnology Information; NGS: next generation sequencing; Nr: database: Non-redundant database; ORF: Open reading frame; RNA-seq: Ribonucleic acid sequencing; RPKM: Reads per kilobase per million mapped reads; SNP: single nucleotide polymorphism; SRA: Sugar Research Australia; SUGIT: sugarcane Iso-Seq transcriptome database; SuSy: sucrose synthase; UDP: uridine diphosphate; UTR: Untranslated region

\section{Acknowledgments}

We gratefully acknowledge the financial support to PPT from the Department of Biotechnology, Government of India, for the Indo-Australian Career Boosting Gold Fellowship and Department of Science and Technology-Science and Engineering Research Board for funding a project (DST No: SB/EMEQ-302/2013) on sequencing whole transcriptomes from Saccharum progenitor species. We are grateful to the Australian Agency for International Development (AusAID) for financial support through an Australian Awards Scholarship to NH. We thank SRA staff in Brandon station, Burdekin, Queensland, Australia for helping with the sample collecting and processing.

\section{Funding}

This work was funded by the Queensland Government, Sugar Research Australia (SRA), Department of Biotechnology, Government of India, Department of Science and Technology-Science and Engineering Board and the Australian Agency for International Development (AusAID). The funders had no role in the design of the study, collection, analysis, and interpretation of data, nor in writing the manuscript.

\section{Availability of data and materials}

The version of SUGIT database used in this study can be accessed in Figshare under the DOI https://doi.org/10.6084/m9.figshare.4981655 or directly at URL: https://doi.org/10.6084/m9.figshare.4981655. The progenitor data (Saccharum officinarum and S. spontaneum) can be accessed in Figshare at https://doi.org/10.6084/m9.figshare.4981673. The RNA-seq data used for expression profiling has been deposited in the NCBI Sequence Read Archive (SRA) under the BioProject ID PRJNA479814, Study Accession Number SRP152893. Other relevant data that supports the finding in this study are included within the article and Additional files 1 and 2.

\section{Authors' contributions}

$\mathrm{RJH}, \mathrm{AF}, \mathrm{FCB}, \mathrm{NVH}$ and PJM conceived and designed the experiments. AF, PJM and NVH collected the samples. PPT, PJM, NVH and AF conducted analyses. PPT prepared the first draft. RJH, AF, FCB, NVH and PJM critically revised the manuscript. All authors read and approved the final manuscript. 


\section{Ethics approval and consent to participate}

Sugarcane commercial genotypes and germplasm collection were collected from the field planting at Sugar Research Australia's Brandon station, Queensland, Australia. No ethics approval was required for the conduct of experiments in this study.

\section{Consent for publication}

Not applicable.

\section{Competing interests}

Author Frederik Botha is an employee of Sugar Research Australia and has authority to conduct this research.

\section{Publisher's Note}

Springer Nature remains neutral with regard to jurisdictional claims in published maps and institutional affiliations.

\section{Author details}

${ }^{1}$ Centre for Plant Sciences, Queensland Alliance for Agriculture and Food Innovation, The University of Queensland, 306 Carmody Road, St. Lucia, Queensland 4072, Australia. ${ }^{2}$ Crop Improvement Division, ICAR-Sugarcane Breeding Institute, Coimbatore, India. ${ }^{3}$ Department of Plant Biotechnology, College of Agriculture and Forestry, Hue University, Hue, Vietnam. ${ }^{4}$ Sugar Research Australia, Indooroopilly, Queensland 4068, Australia.

\section{Received: 8 December 2017 Accepted: 20 March 2019}

\section{Published online: 25 April 2019}

\section{References}

1. Koch K. Sucrose metabolism: regulatory mechanisms and pivotal roles in sugar sensing and plant development. Curr Opin Plant Biol. 2004;7(3):235-46.

2. Winter $\mathrm{H}$, Huber SC. Regulation of sucrose metabolism in higher plants: localization and regulation of activity of key enzymes. Crit Rev Biochem Mol Biol. 2000;35(4):253.

3. Cheng W-H, Tallercio EW, Chourey PS. The Miniature1 seed locus of maize encodes a Cell Wall Invertase required for Normal development of endosperm and maternal cells in the pedicel. Plant Cell. 1996:8(6):971-83.

4. Sturm A, Tang G-Q. The sucrose-cleaving enzymes of plants are crucial for development, growth and carbon partitioning. Trends Plant Sci. 1999:4(10):401-7.

5. Ruan Y-L, Llewellyn DJ, Furbank RT. Suppression of sucrose synthase gene expression represses cotton Fiber cell initiation, elongation, and seed development. Plant Cell. 2003;15(4):952-64.

6. Barratt DHP, Derbyshire P, Findlay K, Pike M, Wellner N, Lunn J, Feil R, Simpson C, Maule AJ, Smith AM. Normal growth of Arabidopsis requires cytosolic invertase but not sucrose synthase. Proc Natl Acad Sci U S A. 2009; 106(31):13124-9.

7. Chen A, He S, Li F, Li Z, Ding M, Liu Q, Rong J. Analyses of the sucrose synthase gene family in cotton: structure, phylogeny and expression patterns. BMC Plant Biol. 2012;12(1):85.

8. Chourey P, Taliercio E, Carlson S, Ruan Y-L. Genetic evidence that the two isozymes of sucrose synthase present in developing maize endosperm are critical, one for cell wall integrity and the other for starch biosynthesis. Mol Gen Genet MGG. 1998:259(1):88-96.

9. Duncan KA, Hardin SC, Huber SC: The three maize [Zea mays] sucrose synthase isoforms differ in distribution, localization, and phosphorylation. The three maize [Zea mays] sucrose synthase isoforms differ in distribution, localization, and phosphorylation 2006(7):959-971.

10. Hirose T, Scofield GN, Terao T. An expression analysis profile for the entire sucrose synthase gene family in rice. Plant Sci. 2008:174(5):534-43.

11. Xiao X, Tang C, Fang Y, Yang M, Zhou B, Qi J, Zhang Y. Structure and expression profile of the sucrose synthase gene family in the rubber tree: indicative of roles in stress response and sucrose utilization in the laticifers. FEBS J. 2014;281(1):291-305.

12. Zhang C, Yu M, Ma R, Shen Z, Zhang B, Korir NK. Structure, expression profile, and evolution of the sucrose synthase gene family in peach (Prunus persica). Acta Physiol Plant. 2015;37(4):81.

13. Botha FC, Black KG. Sucrose phosphate synthase and sucrose synthase activity during maturation of internodal tissue in sugarcane. Australian Journal of Plant Physiology. 2000; 27(1):81-5.

14. Lingle SE. Sugar metabolism during growth and development in sugarcane internodes. Crop Sci. 1999;39(2):480-6.
15. Lingle SE, Dyer JM. Cloning and expression of sucrose synthase-1 cDNA from sugarcane. J Plant Physiol. 2001;158(1):129-31.

16. Schäfer WE, Rohwer JM, Botha FC. Protein-level expression and localization of sucrose synthase in the sugarcane culm. Physiol Plant. 2004;121(2):187-95.

17. Schäfer WE, Rohwer JM, Botha FC. Partial purification and characterisation of sucrose synthase in sugarcane. J Plant Physiol. 2005;162(1):11-20.

18. Zhang J, Arro J, Chen Y, Ming R. Haplotype analysis of sucrose synthase gene family in three Saccharum species. BMC Genomics. 2013;14:314.

19. Gerber L, Zhang B, Roach M, Rende U, Gorzsás A, Kumar M, Burgert I, Niittylä T, Sundberg B. Deficient sucrose synthase activity in developing wood does not specifically affect cellulose biosynthesis, but causes an overall decrease in cell wall polymers. New Phytol. 2014;203(4):1220-30.

20. Zeng Y-D, Sun J-L, Bu S-H, Deng K-S, Tao T, Zhang Y-M, Zhang T-Z, Du X-M, Zhou B-L. ECOTILLING revealed SNPs in GhSus genes that are associated with fiber- and seed-related traits in upland cotton. Sci Rep. 2016;6:29250.

21. Goldner W, Thom M, Maretzki A. Sucrose metabolism in sugarcane cell suspension cultures. Plant Sci. 1991;73(2):143-7.

22. Lingle SE, Irvine JE. Sucrose synthase and natural ripening in sugarcane. Crop Sci. 1994;34(5):1279-83.

23. Zhu YJ, Komor E, Moore PH. Sucrose accumulation in the sugarcane stem is regulated by the difference between the activities of soluble acid Invertase and sucrose phosphate synthase. Plant Physiol. 1997;115(2):609-16.

24. Baroja-Fernández E, Muñoz FJ, Montero M, Etxeberria E, Sesma MT, Ovecka M, Bahaji A, Ezquer I, Li J, Prat S, et al. Enhancing sucrose synthase activity in transgenic potato (Solanum tuberosum L.) tubers results in increased levels of starch, ADPglucose and UDPglucose and Total yield. Plant Cell Physiol. 2009;50(9):1651-62.

25. Sebkova V, Unger C, Hardegger M, Sturm A. Biochemical, physiological, and molecular characterization of sucrose synthase from Daucus carota. Plant Physiol. 1995;108(1):75-83.

26. Tang G-Q, Sturm A. Antisense repression of sucrose synthase in carrot (Daucus carota L.) affects growth rather than sucrose partitioning. Plant Mol Biol. 1999;41(4):465-79.

27. Barratt DHP, Barber L, Kruger NJ, Smith AM, Wang TL, Martin C. Multiple, distinct isoforms of sucrose synthase in pea. Plant Physiol. 2001;127(2):655-64.

28. Baroja-Fernández E, Muñoz FJ, Li J, Bahaji A, Almagro G, Montero M, Etxeberria E, Hidalgo M, Sesma MT, Pozueta-Romero J. Sucrose synthase activity in the sus1/sus2/sus3/sus4 Arabidopsis mutant is sufficient to support normal cellulose and starch production. Proc Natl Acad Sci. 2012; 109(1):321-6.

29. Subbaiah CC, Palaniappan A, Duncan K, Rhoads DM, Huber SC, Sachs MM. Mitochondrial localization and putative signaling function of sucrose synthase in maize. J Biol Chem. 2006;281(23):15625.

30. Daloso DM, Williams TCR, Antunes WC, Pinheiro DP, Müller C, Loureiro ME, Fernie AR. Guard cell-specific upregulation of sucrose synthase 3 reveals that the role of sucrose in stomatal function is primarily energetic. New Phytol. 2016;209(4):1470-83.

31. Baier MC, Keck M, Gödde V, Niehaus K, Küster H, Hohnjec N. Knockdown of the symbiotic sucrose synthase MtSucS1 affects Arbuscule maturation and maintenance in mycorrhizal roots of Medicago truncatula. Plant Physiol. 2010;152(2):1000-14

32. Baud S, Vaultier MN, Rochat C. Structure and expression profile of the sucrose synthase multigene family in Arabidopsis. J Exp Bot. 2004;55(396):397-409.

33. Horst I, Welham T, Kelly S, Kaneko T, Sato S, Tabata S, Parniske M, Wang TL. TILLING mutants of Lotus japonicus reveal that nitrogen assimilation and fixation can occur in the absence of nodule-enhanced sucrose synthase. Plant Physiol. 2007;144(2):806-20.

34. Cho J-I, Kim H-B, Kim C-Y, Hahn T-R, Jeon J-S. Identification and characterization of the duplicate Rice sucrose synthase genes OSSUS5 and OSSUS7 which are associated with the plasma membrane. Mol Cells. 2011;31(6):553-61.

35. Zou C, Lu C, Shang H, Jing $X$, Cheng H, Zhang Y, Song G. Genome-wide analysis of the Sus gene family in cotton. J Integr Plant Biol. 2013:55(7):643-53.

36. Zhu X, Wang M, Li X, Jiu S, Wang C, Fang J. Genome-wide analysis of the sucrose synthase gene family in grape (Vitis vinifera): structure, evolution, and expression profiles. Genes. 2017:8(4):111.

37. Carson DL, Huckett BI, Botha FC, van Staden J. Differential gene expression in sugarcane leaf and internodal tissues of varying maturity. S Afr J Bot. 2002:68(4):434-42

38. Wang Z, Wei P, Wu M, Xu Y, Li F, Luo Z, Zhang J, Chen A, Xie X, Cao P, et al Analysis of the sucrose synthase gene family in tobacco: structure, phylogeny, and expression patterns. Plant. 2015;242(1):153-66. 
39. Sturm A. Invertases. Primary Structures, Functions, and Roles in Plant Development and Sucrose Partitioning. Plant Physiol. 1999;121(1):1.

40. Joshi CP, Bhandari S, Ranjan P, Kalluri UC, Liang X, Fujino T, Samuga A. Genomics of cellulose biosynthesis in poplars. New Phytol. 2004;164(1):53-61.

41. Koch KE, Nolte KD, Duke ER, McCarty DR, Avigne WT. Sugar levels modulate differential expression of maize sucrose synthase genes. Plant Cell. 1992;4(1):59-69.

42. Haagenson DM, Klotz KL, McGrath JM. Sugarbeet sucrose synthase genes differ in organ-specific and developmental expression. J Plant Physiol. 2006;163(1):102-6.

43. Komatsu A, Moriguchi T, Koyama K, Omura M, Akihama T. Analysis of sucrose synthase genes in citrus suggests different roles and phylogenetic relationships. J Exp Bot. 2002;53(366):61-71.

44. Hartt CE, Kotschak HP, Forbes A, Burr GO. Translocation of $14 \mathrm{C}$ in sugarcane. Plant Physiol. 1963;38:305-18.

45. Lingle SE. Seasonal internode development and sugar metabolism in sugarcane. Crop Sci. 1997;37:1222-7.

46. Lingle SE, Viator RP, Johnson RM, Tew TL, Boykin DL. Recurrent selection for sucrose content has altered growth and sugar accumulation in sugarcane. Field Crops Res. 2009;113(3):306-11.

47. Botha FC, Whittaker A, Vorster DJ, Black KG, Wilson JR, Hogarth DM Campbell JA, Garside AL. Sucrose accumulation rate, carbon partitioning and expression of key enzyme activities in sugarcane stem tissue, Sugar 2000 Symposium: Sugarcane: research towards efficient and sustainable production; 1996. p. 98-101.

48. Whittaker A, Botha F. Carbon partitioning during sucrose accumulation in sugarcane internodal tissue. Plant Physiol. 1997:115(4):1651-9.

49. Sinclair T, Gilbert R, Perdomo R, Shine J, Powell G, Montes G. Volume of individual internodes of sugarcane stalks. Field Crop Res. 2005;91(2):207-15.

50. Wang J, Nayak S, Koch K, Ming R. Carbon partitioning in sugarcane (Saccharum species). Front Plant Sci. 2013:4:201.

51. Welbaum GE, Meinzer FC. Compartmentation of solutes and water in developing sugarcane stalk tissue. Plant Physiol. 1990;93(3):1147-53.

52. Chen Z-L, Gui Y-Y, Qin C-X, Wang M, Liao Q, Huang D-L, Li Y-R. Isolation and expression analysis of sucrose synthase gene (ScSuSy4) from sugarcane. Sugar Tech. 2016;18(2):134-40.

53. Kukurba KR, Montgomery SB. RNA sequencing and analysis. Cold Spring Harb Protoc. 2015;2015(11):951-69.

54. Aitken KS, McNeil MD, Hermann S, Bundock PC, Kilian A, Heller-Uszynska K, Henry RJ, Li J. A comprehensive genetic map of sugarcane that provides enhanced map coverage and integrates high-throughput diversity Array technology (DArT) markers. BMC Genomics. 2014;15(1):152.

55. Zhang C, Yu M, Ma R, Shen Z, Zhang B, Korir N. Structure, expression profile, and evolution of the sucrose synthase gene family in peach ( Prunus persica ). Acta Physiol Plant. 2015;37(4):1-15.

56. Hoang NV, Furtado A, Mason PJ, Marquardt A, Kasirajan L, Thirugnanasambandam PP, Botha FC, Henry RJ. A survey of the complex transcriptome from the highly polyploid sugarcane genome using fulllength isoform sequencing and de novo assembly from short read sequencing. BMC Genomics. 2017;18(1):395.

57. Nei M, Gojobori T. Simple methods for estimating the numbers of synonymous and nonsynonymous nucleotide substitutions. Mol Biol Evol. 1986;3(5):418-26.

58. Kumar S, Stecher G, Tamura K. MEGA7: molecular evolutionary genetics analysis version 7.0 for bigger datasets. Mol Biol Evol. 2016;33(7):1870-4.

59. Tamura K, Peterson D, Peterson N, Stecher G, Nei M, Kumar S. MEGA5: molecular evolutionary genetics analysis using maximum likelihood, evolutionary distance, and maximum parsimony methods. Mol Biol Evol. 2011;28(10):2731-9.

60. Furtado A. RNA extraction from developing or mature wheat seeds. Cereal Genomics. 2014:1099:23-8.

61. Thirugnanasambandam PP, Meena SA, Suparna TV, Kasirajan L, Selvi A. Comparative transcriptome analysis of the progenitor species of sugarcane for sucrose and fibre genes, Proceedings of the International Symposium on Sugarcane Research since Co 205: 100 Years and Beyound September 1821,2017,India; 2017. p. 238

62. Hoang NV, Furtado A, Donnan L, Keeffe EC, Botha FC, Henry RJ. Highthroughput profiling of the Fiber and sugar composition of sugarcane biomass. Bioenerg Res. 2016;10(2):400-16.

63. Kolde Rpheatmap: Pretty heatmaps. R package version 1.0. 8. https://CRANRprojectorg/package=pheatmap 2015.

64. Kolde R. pheatmap: Pretty heatmaps [Software]; 2015.
65. Riaño-Pachón DM, Mattiello L. Draft genome sequencing of the sugarcane hybrid SP80-3280. F1000Res. 2017;6:861

66. Lecharny A, Boudet N, Gy I, Aubourg S, Kreis M. Introns in, introns out in plant gene families: a genomic approach of the dynamics of gene structure. Journal of Structural and Functional Genomics. 2003;3(1-4):111-6.

67. Xu G, Guo C, Shan H, Kong H. Divergence of duplicate genes in exonintron structure. Proc Natl Acad Sci. 2012;109(4):1187-92.

68. Chopra S, Del-favero J, Dolferus R, Jacobs M. Sucrose synthase ofArabidopsis: genomic cloning and sequence characterization. Plant Mol Biol. 1992;18(1):131-4.

69. Werr W, Frommer WB, Maas C, Starlinger P. Structure of rhe sucrose synthase gene on chromosome 9 of Zea mays L. EMBO J. 1985;4(6):1373-80.

70. Yu S, Cao L, Zhou C-M, Zhang T-Q, Lian H, Sun Y, Wu J, Huang J, Wang G, Wang J-W. Sugar is an endogenous cue for juvenile-to-adult phase transition in plants. eLife. 2013;2:e00269.

71. An X, Chen Z, Wang J, Ye M, Ji L, Wang J, Liao W, Ma H. Identification and characterization of the Populus sucrose synthase gene family. Gene. 2014; 539(1):58-67.

72. Fu H, Kim SY, Park WD. High-level tuber expression and sucrose inducibility of a potato Sus4 sucrose synthase gene require 5'and 3'flanking sequences and the leader intron. Plant Cell. 1995;7(9):1387-94.

73. Zrenner R, Salanoubat M, Willmitzer L, Sonnewald U. Evidence of the crucial role of sucrose synthase for sink strength using transgenic potato plants (Solanum tuberosum L.). Plant J. 1995;7(1):97-107.

74. Thirugnanasambandam PP, Hoang NV, Henry RJ. The Challenge of Analyzing the Sugarcane Genome. Front Plant Sci. 2018;9:616.

75. Zhang D, Xu B, Yang X, Zhang Z, Li B. The sucrose synthase gene family in Populus : structure, expression, and evolution. Tree Genet Genomes. 2011; 7(3):443-56.

76. Hardin S, Duncan K, Huber S. Determination of structural requirements and probable regulatory effectors for membrane Association of Maize Sucrose Synthase 1(1). Plant Physiol. 2006;141(3):1106-19.

77. Barrero-Sicilia C, Hernando-Amado S, González-Melendi P, Carbonero P. Structure, expression profile and subcellular localisation of four different sucrose synthase genes from barley. Planta. 2011;234(2):391-403.

78. Volpicella M, Fanizza I, Leoni C, Gadaleta A, Nigro D, Gattulli B, Mangini G, Blanco A, Ceci LR. Identification and Characterization of the Sucrose Synthase 2 Gene ( Sus2) in Durum Wheat. Front Plant Sci. 2016;7:266.

79. Botha F, Whittaker A, Vorster D, Black K. Sucrose accumulation rate, carbon partitioning and expression of key enzyme activities in sugarcane stem tissue. In: Wilson, J.R., Hogarth, D.M., Campbell, J.A. and Garside, A.L. ed. Sugarcane: Research towards Efficient and Sustainable Production. Bnsbane, CSIRO Division of Tropical Crops and Pastures. 1996;98-101.

80. Albrecht $\mathrm{G}$, Mustroph A. Localization of sucrose synthase in wheat roots: increased in situ activity of sucrose synthase correlates with cell wall thickening by cellulose deposition under hypoxia. Planta. 2003;217(2):252-60.

81. Subbaiah CC, Sachs MM. Altered patterns of sucrose synthase phosphorylation and localization precede Callose induction and root tip death in anoxic maize seedlings. Plant Physiol. 2001;125(2):585-94.

82. Lingle $S$. Rates of growth and sugar accumulation in sugarcane related to sucrose synthase activity. In: Wilson, J.R., Hogarth, D.M., Campbell, J.A. and Garside, A.L. ed.Sugarcane: research towards efficient and sustainable production Brisbane: CSIRO Division of Tropical Crops and Pastures. 1996: 95-7.

83. Sun J, Loboda T, Sung S-JS, Black CC. Sucrose synthase in wild tomato, Lycopersicon chmielewskii, and tomato fruit sink strength. Plant Physiol. 1992:98(3):1163-9.

84. Wang F, Sanz A, Brenner ML, Smith A. Sucrose synthase, starch accumulation, and tomato fruit sink strength. Plant Physiol. 1993;101(1):321-7.

85. Thirugnanasambandam PP, Hoang NV, Furtado A, Botha FC, Henry RJ. Association of variation in the sugarcane transcriptome with sugar content. BMC Genomics. 2017;18(1):909. 